J Pers Soc Psychol. 2014 March ; 106(3): 469-483. doi:10.1037/a0035135.

\title{
Continuity and Change in Self-Esteem During Emerging Adulthood
}

\author{
Joanne M. Chung, \\ Department of Psychology, University of California, Davis \\ Richard W. Robins, \\ Department of Psychology, University of California, Davis \\ Kali H. Trzesniewski, \\ Department of Human Development, University of California, Davis \\ Erik E. Noftle, \\ Department of Psychology, Willamette University \\ Brent W. Roberts, and \\ Department of Psychology, University of Illinois, Urbana-Champaign \\ Keith F. Widaman \\ Department of Psychology, University of California, Davis
}

\section{Abstract}

The present study examined the development of self-esteem in a sample of emerging adults $(N=$ 295) followed longitudinally over 4 years of college. Six waves of self-esteem data were available. Participants also rated, at the end of their 4th year, the degree to which they thought their selfesteem had changed during college. Rank-order stability was high across all waves of data (Mdn disattenuated correlation $=.87$ ). On average, self-esteem levels dropped substantially during the 1 st semester $(d=-.68)$, rebounded by the end of the 1st year $(d=.73)$, and then gradually increased over the next 3 years, producing a small $(d=.16)$ but significant mean-level increase in self-esteem from the beginning to the end of college. Individuals who received good grades in college tended to show larger increases in self-esteem. In contrast, individuals who entered college with unrealistically high expectations about their academic achievement tended to show smaller increases in self-esteem, despite beginning college with relatively high self-esteem. With regard to perceived change, $67 \%$ reported that their self-esteem increased during college, whereas $12 \%$ reported that it declined; these perceptions tended to correspond with actual increases and decreases in their self-esteem scale scores $(\beta=.56)$. Overall, the findings support the perspective that self-esteem, like other personality characteristics, can change in systematic ways while exhibiting continuity over time.

(C) 2013 American Psychological Association

Correspondence concerning this article should be addressed to Joanne M. Chung, Department of Psychology, University of California, One Shields Avenue, Davis, CA 95616.jmhchung@ucdavis.edu. 


\section{Keywords}

self-esteem; self-perceived change; emerging adulthood; college transition

Global self-esteem refers to an individual's subjective evaluation of his or her worth as a person. Like other personality characteristics, global self-esteem is moderately stable over time and across contexts (Trzesniewski, Donnellan, \& Robins, 2003). This stable component of self-esteem has been a major research focus and has been shown to promote behaviors, goals, and coping mechanisms that facilitate success in work, school, and relationships and reduce risk for mental and physical health problems, substance abuse, and antisocial behavior (e.g., Crocker \& Luhtanen, 2003; Donnellan, Trzesniewski, Robins, Moffit, \& Caspi, 2005; Orth, Robins, \& Widaman, 2012; Swann, Chang-Schneider, \& Larsen McClarty, 2007; Trzesniewski et al., 2006). In light of these findings, a better understanding of the way self-esteem changes during critical life periods, such as the college years, is an important societal goal.

Although much research conducted to date has emphasized the stability of self-esteem, selfesteem is assumed to be dynamic and responsive to events occurring in one's life. Emerging adulthood (age 18 years to mid-20s) is a period of considerable opportunity and challenge. Many young adults move away from home for the first time, begin college and full-time jobs, or marry and have children. Researchers interested in personality and development have emphasized the importance of this period, describing the complex challenges that young adults face and the patterns of adaptation that follow from their resolution (Arnett, 2011; Erikson, 1964; White, 1966). Given the transitional nature of these years, emerging adulthood may be a time during which global self-esteem is especially likely to change. Moreover, the developmental process of becoming an adult often entails a questioning of one's identity and subsequent reformulation of conceptions and evaluations of the self.

The present study examined consistency and change in self-esteem during emerging adulthood. As in most research on personality development, we examined the rank-order stability of self-esteem as well as mean-level (i.e., normative) change. We also examined predictors of the self-esteem trajectory, attempting to predict who increased or decreased in self-esteem as they progressed through college. We focused on one of the most significant indicators of success in the college context—academic achievement. Specifically, we tested whether individuals who receive good (poor) grades in college tend to increase (decrease) in self-esteem, and whether individuals who enter college expecting to receive very high grades maintain their self-esteem, or experience a drop in self-esteem when they fail to meet their expectations. Finally, we examined individuals' perceptions of how their self-esteem changed during college and the degree to which these perceptions correspond to actual changes in self-esteem. ${ }^{1}$ Below, we review previous research on these topics.

\footnotetext{
${ }^{1}$ We use the term "actual" because we examined actual changes in a person's self-esteem scale scores. We are not necessarily equating these changes in RSE scores with "real" changes in self-esteem. However, if one accepts scales such as the RSE as valid measures of self-esteem, then the present findings can be conceptualized as contrasting perceived and real changes in self-esteem. Indeed, in the literature, self-esteem is most commonly measured using standardized self-report scales, and therefore we are assessing (albeit imperfectly) actual change as it is represented in the current tradition of self-esteem assessment.
} 


\section{Rank-Order Stability of Self-Esteem During College}

Over the past few decades, researchers have debated the degree to which self-esteem should be conceptualized as a trait-like construct that remains relatively stable over time, or as a state-like process that continually fluctuates in response to environmental and situational stimuli (Donnellan, Kenny, Trzesniewski, Lucas, \& Conger, 2012; Kuster \& Orth, 2013; Trzesniewski et al., 2003). If self-esteem is trait-like, then we would expect to find high rank-order stability; that is, individuals who have relatively high (or low) self-esteem at one point in time will tend to have high (or low) self-esteem years later. Rank-order stability is commonly assessed by the correlation between personality scores across two time points, but it can also be evaluated with first-order autoregressive models in structural equation modeling. Rank-order stability is reduced by maturational or experiential factors that differentially affect people's self-esteem, as well as by measurement error.

The rank-order stability of self-esteem varies across the lifespan. Specifically, stability is relatively low during early childhood and increases throughout adolescence and adulthood (Donnellan et al., 2012; Kuster \& Orth, 2013; Trzesniewski et al., 2003). In Trzesniewski et al.'s (2003) meta-analysis, the rank-order stability of self-esteem over a 4-year period for a hypothetical sample of 18-year-olds was .55. Accordingly, we expected to find test-retest estimates in the .50 s over the 4-year period examined in the present study.

\section{Mean-Level Changes in Self-Esteem During College}

As individuals go through life, their self-esteem inevitably waxes and wanes. These fluctuations in self-esteem reflect changes in our social environment as well as maturational changes such as puberty and cognitive declines in old age. When these changes are normative, age-dependent, and affect individuals in a similar manner, they will lead to aggregate (or mean-level) changes in self-esteem over time. Mean-level change is both theoretically and statistically distinct from rank-order stability. Considerable mean-level change does not indicate low rank-order stability, and conversely lack of mean-level change does not indicate high stability. For example, a group of people might increase substantially on a trait, but their rank ordering would stay the same if everyone in the group increased by the same amount. In the same way, the rank ordering of individuals could change substantially over time but not be reflected in aggregate mean-level change (e.g., if the number of people who decrease offsets the number of people who increase).

Although we know that self-esteem shows normative changes across the lifespan (Robins \& Trzesniewski, 2005), there is surprisingly little research examining mean-level change in self-esteem during the critical college period. Recent research suggests that self-esteem gradually increases during the transition from adolescence into adulthood (Erol \& Orth, 2011; Orth, Trzesniewski, \& Robins, 2010; Wagner, Lüdtke, Jonkmann, \& Trautwein, 2013). However, relatively little research has specifically charted changes in self-esteem from the beginning to the end of college. When self-esteem has been assessed at the beginning and end of college, significant mean-level changes have not been found (van der Velde, Feij, \& Taris, 1995). In contrast, two studies that examined self-esteem during the first year of college found a significant decline (Pritchard, Wilson, \& Yamnitz, 2007; Shim, 
Ryan, \& Cassady, 2012). These latter studies suggest that the transition to college may challenge emerging adults' self-views, but the former study suggests that emerging adults are able to maintain their self-esteem across this difficult transition and throughout college. Taken together, these studies suggest a need to examine self-esteem across college in addition to during the transition to college. Such a study could provide insight into what happens after the initial self-esteem drop-do students continue to decline, plateau at a lower level than when they entered college, or show a recovery to their initial level. The present study aims to provide a more precise picture of the specific, year-by-year changes over the entirety of the college experience.

Studies of self-esteem development across the lifespan have found that self-esteem decreases during the transition to adolescence and then increases gradually over the course of adulthood, before declining in old age (Erol \& Orth, 2011; Orth et al., 2012;Robins, Tracy, Trzesniewski, Potter, \& Gosling, 2001). These studies suggest that change can occur in response to transitions or major life events (e.g., Caspi \& Roberts, 2001), although maturational changes such as hormonal changes in puberty (Williams \& Currie, 2000) may also contribute to self-esteem change. For example, Rutter (1996) stated that, although there is stability in many types of behavior from childhood through adulthood, turning points modify or redirect life trajectories; turning points are transitional periods or events that have the potential to alter behavior, affect, cognition, or context, all of which could result in lifelong change. Normative, age-dependent transitions (e.g., leaving home for college) might explain normative change, whereas transitions that are not age dependent (e.g., breaking up with a romantic partner) or nonnormative (e.g., death of close friend or family member) may produce individual differences in change.

The most frequently studied turning point for self-esteem development is the transition to adolescence, which typically coincides with the transition to junior high school. This school transition has been implicated as a major cause of the adolescent self-esteem drop (e.g., Eccles, Wigfield, Flanagan, \& Miller, 1989;Eccles, Wigfield, Midgley, \& Reuman, 1993; Marsh, 1989; Simmons, Blyth, Van Cleave, \& Bush, 1979; Wigfield \& Eccles, 1994). However, the findings regarding this claim are somewhat inconsistent (Blyth, Simmons, \& Bush, 1978; Hirsch \& Rapkin, 1987; Nottleman, 1987), perhaps because children go through puberty and transition to middle and junior high school at different ages. Thus, a more homogenous transition such as the transition into college (where maturational changes may be less likely to play a role) is needed for studying the impact of a potentially stressful life transition on self-esteem development.

Because the transition to college involves changes in school environment, social ties, expectations from others, and expectations for oneself, self-esteem change during the transition to college may parallel the transition to junior high school. Studies of the transition to adolescence suggest that the experience of changing school contexts can result in an immediate negative impact on self-esteem. Accordingly, we believe that the transition to college constitutes a developmental turning point that, on average, negatively impacts the self-esteem of young adults. In summary, previous research has found little or no change in mean levels of self-esteem from the beginning to the end of college. However, these studies have not examined change periodically throughout the college years. 


\section{Academic Achievement and Self-Esteem}

One of the most salient features of the transition from high school to college is the increasing level of academic rigor and competitiveness that most students experience. This has been described as moving from being a "big fish in a little pond" to being a "little fish in a big pond." This transition has been shown to negatively impact self-esteem as students' high initial expectations clash with the reality of competing with other "big fish" for good grades, and the inevitable failure that follows for many of them (Marsh \& Hau, 2003). Given the centrality of academic achievement in the college context, we focused on how the selfesteem trajectory is shaped by students' initial expectations for their college grades and the actual grades they end up receiving.

In general, the research literature suggests that school grades are positively associated with high self-esteem. For example, in Hansford and Hattie's (1982) meta-analysis, the estimated effect size between various self-beliefs (e.g., self-esteem, self-acceptance, academic selfconcept, etc.) and various academic outcomes (e.g., grade-point average [GPA], test scores, etc.) was .21. In a more recent meta-analysis, researchers examined the prospective influence of self-beliefs on academic achievement, in student samples that spanned preschool to college (Valentine, DuBois, \& Cooper, 2004). Results of this meta-analysis indicated that self-beliefs positively predicted later academic achievement, with an estimated effect size (standardized Beta weight) of .08. Additionally, Marsh and Craven (2006) provided evidence for reciprocal influence: Self-beliefs in the academic domain positively predicted later academic achievement, and, conversely, academic achievement positively predicted later self-beliefs; however, these effects held only for academic self-concept, not global self-esteem. In summary, previous research has found that higher levels of selfesteem, particularly domain-specific self-esteem (i.e., academic self-beliefs), are concurrently and longitudinally associated with academic achievement. However, these studies have not examined whether changes in academic achievement are associated with changes in self-esteem across 4 years of college.

We also examined the influence of expected grades on self-esteem change. We know of no research that directly addresses this question, but previous research has consistently shown that college students have inflated expectations about their grades (Beyer, 1999; Garavalia \& Gredler, 2002; Nowell \& Alston, 2007; Svanum \& Aigner, 2011; Wendorf, 2002), raising the possibility that self-esteem will be negatively impacted when students fail to meet their unrealistic expectations. Another related line of research shows that highly narcissistic students are more likely to expect high grades than less narcissistic students, independent of their actual ability (Farwell \& Wohlwend-Lloyd, 1998), suggesting that overly inflated selfviews are associated with inflated expectations for grades. Thus, given the tendency for narcissistic individuals to report high self-esteem, we expect to find a link between high expected grades and higher levels of self-esteem. However, over the long term, as narcissistic illusions about getting straight A's confront the objective reality of academic mediocrity, we expect that people who think they will receive better grades than they actually receive will show declines in self-esteem over time. To address this question, we examined the effects of expected grades on self-esteem change, controlling for actual grades. By partialing actual grades out of expected grades, we are taking "reality" out of 
their expectations and examining whether people who have unrealistically positive expectations about their grades show increases or decreases in self-esteem over time (this is a variant on the use of residualized discrepancy scores in the self-enhancement literature; Kwan, John, Kenny, Bond, \& Robins, 2004; Schriber \& Robins, 2012).

\section{Perceived Change in Self-Esteem}

To our knowledge, no published studies have compared individuals' perceptions of how their self-esteem has changed to actual change in their self-esteem scores. However, related research suggests that people retrospectively report large changes in their personality, despite showing relatively minor changes in their personality test scores (Fleeson \& Heckhausen, 1997; Haslam, Fox, \& Whelan, 2007; Robins, Noftle, Trzesniewski, \& Roberts, 2005; Staudinger, Bluck, \& Herzberg, 2003; Wilson \& Ross, 2001; Woodruff, 1983; Woodruff \& Birren, 1972). The discrepancy between folk notions of substantial and often dramatic personality change and empirical findings indicating modest, gradual personality change suggests that people may not be very accurate at describing their own personality development. These findings are consistent with theorizing that people tend to derogate past selves in order to make their current self feel better (Wilson \& Ross, 2001), a process that would tend to decrease the correspondence between perceived and actual personality change.

The few studies have that correlated individual differences in perceived personality change with actual changes in personality have produced mixed results. For example, Costa, McCrae, and colleagues concluded from their research that people's perceptions of how their Big Five scores have changed over time are largely inaccurate (Costa \& McCrae, 1989; Herbst, McCrae, Costa, Feaganes, \& Siegler, 2000). In contrast, Robins et al. (2005) pointed to modest but statistically significant correlations ( $r=.15$ to .33 ) between perceived and actual change in the Big Five during college to argue that people have at least some insight into the way their personality changes over time.

The literature on perceived change in personality suggests that there might not be a strong correspondence between perceived and actual change in self-esteem. However, of all the developmental stages, we might expect to find the strongest correspondence during emerging adulthood, because young adults are actively focused on identity issues (Erikson, 1964; Harter, 1999; Pals, 1999) and engaging in a process of "open exploration" (Fleeson \& Heckhausen, 1997, p. 134). Constructing one's identity necessitates a good deal of selfreflection, which may promote insight into one's life history and experiences. Moreover, there is a substantial amount of intraindividual variability in changes in self-esteem during this developmental phase (as evidenced by relatively low rank-order stability; Trzesniewski et al., 2003), which should increase the range of individual differences in self-esteem, making it easier to find stronger correlations between perceived and actual change.

\section{Present Study}

The present study examined self-esteem continuity and change in emerging adulthood using longitudinal data on a large sample of young adults followed through their college years. Participants completed the Rosenberg (1965) Self-Esteem scale six times over the course of 
college. These data provide a unique opportunity to learn more about self-esteem change during an important developmental transition. More specifically, the present research addresses four main questions concerning self-esteem development in emerging adulthood: First, to what extent are individual differences in self-esteem stable through the college years? Second, what is the trajectory of self-esteem over the course of college; that is, are there mean-level increases or decreases in self-esteem during this time? Third, to what extent do changes in grades and discrepancies between expected and actual grades predict self-esteem change? Fourth, to what extent do young adults think their self-esteem has changed, and how well do these perceptions correspond to actual changes in self-esteem scores?

\section{Method}

\section{Sample and Procedure}

This research used data from the Berkeley Longitudinal Study, a longitudinal study designed to examine the development of self-esteem and personality during college (for further details about the study, see Noftle \& Robins, 2007; Robins \& Beer, 2001;Robins, Fraley, Roberts, $\&$ Trzesniewski, 2001; Robins et al., 2005). ${ }^{2}$ Participants were recruited during the first week of their first year of college and then assessed annually throughout college.

Participants were contacted by mail and asked to complete an extensive questionnaire in exchange for financial compensation. Six assessments were conducted over a 4-year period: first week of college $(N=508)$; end of the first semester $(N=455)$; and end of the first $(N=$ $306)$, second $(N=260)$, third $(N=200)$, and fourth $(N=303)$ years of college. The Rosenberg Self-Esteem Scale (Rosenberg, 1965) was administered at every assessment: first week of college $(N=489)$; end of the first semester $(N=405)$; and end of the first $(N=$ $306)$, second $(N=295)$, third $(N=197)$, and fourth $(N=303)$ years of college. Our analyses focused on a subsample of participants $(N=295)$ who completed the relevant measures at the first and last assessments (first week and fourth year). On most variables of interest, there were no differences between participants and nonparticipants. However, participants received significantly higher grades throughout college than non-participants $(M d n=.24$ grade points across the eight assessments, $p s<.05)$ and were more likely to be women $(60 \%$ vs. $50 \%, p<.05)$. In light of these differences, the participants in the study may not represent an unbiased sample of the original study participants.

The sample was diverse in terms of ethnicity (43\% Asian, 36\% Caucasian, $12 \%$ Chicano/ Latino, 5\% African American, 4\% Missing/Other/Multiracial), sex (60\% female), socioeconomic status (20\% came from families with 1992 household incomes below $\$ 25,000$ and $17 \%$ from families with household incomes above \$100,000), and academic ability (combined verbal and math SAT scores ranged from 650 to 1,$530 ; M=1,194, S D=$ 173).

\footnotetext{
${ }^{2}$ The following articles also report self-esteem findings using data from the Berkeley Longitudinal Study: Orth, Robins, and Meier (2009); Orth, Robins, and Roberts (2008); Robins and Beer (2001); Robins, Hendin, and Trzesniewski (2001); Robins and Pals (2002). However, the research questions addressed by these studies overlap only minimally with the present study.
} 


\section{Measures}

Demographic variables-Participants self-reported their ethnicity, sex, and socioeconomic status (SES; see Table 1 for correlations among demographic variables). To retain adequate sample sizes, we classified participants as Caucasian, Asian, or non-Asian minority; this variable was dummy coded with Caucasians as the reference group. Sex was coded as 0 (male) and 1 (female). Socioeconomic status (SES) ranged from 1 (low SES) to 5 (high SES). The SES variable is a composite of three items that assessed mother's highest level of education completed, father's highest level of education completed, and annual family income.

Self-esteem-Participants completed the 10-item Rosenberg Self-Esteem (RSE; Rosenberg, 1965) scale three times during the first year of college, and then annually for the next 3 years (alpha reliability ranged from .89 to .91 ; see Table 1 for all estimates). Items were rated on a 5-point scale ranging from 1 (not very true of me) to 5 (very true of me). To examine change in self-esteem, we conducted a latent growth curve model (LGCM; Bollen $\&$ Curran, 2006) using all six RSE assessments.

Academic achievement-Student GPAs (on a 0.00 to 4.00 scale) were obtained from university records every semester for 4 years (eight assessments total).

Expected academic achievement-During the first week of college, participants were asked three questions about their expected performance in college: "What overall GPA do you think you are capable of attaining at UC Berkeley?" "Realistically, what overall GPA do you think you will attain at UC Berkeley?" "What is the lowest overall GPA you would be satisfied attaining at UC Berkeley?" (alpha reliability $=.87$ ). For all three items, responses were made on a GPA scale ranging from 0.00 (all F's) to 4.00 (all A's).

Perceived self-esteem change-Perceived self-esteem change was assessed at the end of the fourth year of college. Participants were asked to rate how their "self-esteem, selfconfidence" has changed since they entered college. The rating scale ranged from 1 (decreased) to 5 (increased), with the midpoint labeled stayed the same. Past research has demonstrated that single-item measures, such as our measure of perceived self-esteem change, can have adequate reliability and validity (Gosling, Rentfrow, \& Swann, 2003; Postmes, Haslam, \& Jans, 2012; Robins, Fraley, et al., 2001).

\section{Results}

\section{Rank-Order Stability of Self-Esteem}

To examine the rank-order stability of self-esteem during college, we used structural equation modeling to fit a first-order autoregressive model to the six assessments. First-order autoregressive models are often used to examine repeated measures data. Whereas traditional OLS methods treat autocorrelation as a statistical nuisance, first-order autoregressive models take into account the dependency of the previous assessment on subsequent assessments so that each assessment is composed of a random error component and the previous assessment. First-order autoregressive models provide estimates of the 
latent variable separately from error, allowing for stability estimates that have been corrected for reliability of the measure. We fit a first-order autoregressive model that allowed for the estimation of measurement error, fixing the measurement error to be equal across assessments (see Figure 1 for model and estimates). Rank-order stability for selfesteem was consistently high, with standardized estimates ranging from .89 to $.95, M d n=$. 90. See Table 1 for stability correlations between all assessments.

A second, less often examined issue is whether the amount of individual variability in selfesteem (i.e., the variance of self-esteem scores) changed systematically across assessments. To address this issue, we first fit a fully unconstrained model to the six self-esteem assessments in which we freely estimated means, variances, and covariances of the manifest variables. Variance estimates were .56 (Week 1), .38 (Semester 1), .61 (Year 1), .61 (Year 2), .55 (Year 3), and .55 (Year 4). Not surprisingly, given the comparatively low Semester 1 variance, a model in which all variances were constrained to be equal did not fit the data well, $\chi^{2}(5)=41.452, p=.00$, root-mean-square error of approximation $($ RMSEA $)=.157$, $90 \%$ confidence interval $(\mathrm{CI})[.115, .203], p_{\text {close fit }}=.000$, comparative fit index $(\mathrm{CFI})=$. 967, Tucker-Lewis index (TLI) $=.900$. To improve model fit, we allowed the variance for Semester 1 to be freely estimated, but constrained all other variances to be equal. This model fit significantly better than the fully constrained model, $\chi_{\text {change }}{ }^{2}(1)=38.737, p=.000$, and had good fit to the data, $\chi^{2}(4)=2.715, p=.61$, RMSEA $=.000,90 \%$ CI [.000, .074], $p_{\text {close fit }}=.843, \mathrm{CFI}=1.000, \mathrm{TLI}=1.004$ Thus, the first semester of college seems to have reduced individual variability in self-esteem, but the amount of variance returned to initial levels at all subsequent time points.

\section{Mean-Level Change in Self-Esteem}

Figure 2 shows mean levels of self-esteem at each assessment. The trajectory of self-esteem was examined using latent growth curve modeling (LGCM), which is ideal for examining mean-level change as well as individual differences in change. In an LGCM, observed variables are represented by a latent intercept, reflecting initial levels of the variable, and a latent slope, representing growth in this variable over time. In the present study, we specified a modified LGCM, given the unique pattern shown at Semester 1 and the uneven spacing of assessments. The slope was centered at the first time of measurement, so this coefficient was 0 . The two remaining assessments in the first year were at the end of first semester and end of first year, or .375 and .750 years after the first assessment, respectively. The remaining assessments - at the end of the second, third, and fourth years of collegewere annual assessments subsequent to the "end of first year" assessment, so were given coefficients of $1.75,2.75$, and 3.75, respectively. In addition to the latent intercept and latent slope variables, we added a single-indicator latent variable to represent the large decrease in self-esteem that occurred at Semester 1. In a previous iteration of this model, the residual variance estimate of the Semester 1 assessment was negative, representing a Heywood case. However, the residual variance of the Semester 1 assessment was not significantly different from 0 , and consequently, the Semester 1 assessment was fixed at 0 to allow for more appropriate estimates. For all other assessments, residual variance was estimated to be equal. Below we refer to the latent intercept as the self-esteem intercept, the single-indicator latent 
variable as the 1st semester slope, and the latent slope as the 4-year slope. These variables were all allowed to covary with each other.

We first fit an unconditional model (Model 0) to determine whether there was an average, or typical, trajectory of self-esteem throughout the college years (see Figure 3). This model yielded good fit, $\chi^{2}(17, N=295)=44.788$, RMSEA $=.074,90 \%$ CI $[.048, .101], p_{\text {closefit }}=$. $061, \mathrm{CFI}=.974, \mathrm{TLI}=.977$. The means of the intercept, first semester slope, and 4-year slope all differed significantly from zero, indicating that people started out at an average level of self-esteem, that people tended to decrease in self-esteem during the first semester of college, and that people tended to increase in self-esteem over the 4 years of college. The variance of each of the three latent variables was also significant, suggesting that there was individual variability around the average trajectory. Despite this variability, the decline in self-esteem occurring during the first semester was highly normative, with the variability in the slope largely reflecting differences in the degree to which people declined in selfesteem, not whether they exhibited a decline.

In terms of the correlations among the intercept and slope variables, the intercept was negatively associated with the first-semester slope, indicating that people who entered college with higher self-esteem tended to show less steep declines in self-esteem during their first semester of college than those who entered college with lower self-esteem. The intercept was negatively associated with the 4-year slope, indicating that the higher people's self-esteem, the less they increased in self-esteem across college. However, the 1st semester slope was not significantly associated with the 4-year slope, indicating that the decrease in self-esteem occurring during the first semester of college was not associated with overall change in self-esteem throughout college.

We next fit a conditional model (Model 1) to examine the potential moderating effects of our demographic variables, entering participant sex, race, and SES as time-invariant covariates in our model. The conditional model yielded good fit, $\chi^{2}(29, N=295)=60.049$, RMSEA $=.060,90 \%$ CI $[.038, .082], p_{\text {closefit }}=.202, \mathrm{CFI}=.974, \mathrm{TLI}=.960$. Significant effects of participant sex and SES were found on the intercept, indicating that females and those of lower SES started out with lower self-esteem in college than males and those of higher SES. The effects of demographic variables on the first semester slope and 4-year slope variables were nonsignificant, indicating that the trajectory of self-esteem throughout the college years was similar across sex, race, and SES (See Table 2 for estimates).

\section{Predicting the Self-Esteem Trajectory From Actual and Expected Academic Achievement}

Do individuals who receive good grades show increases in self-esteem as they go through college, and conversely do those who receive poor grades tend to decline in self-esteem? To address this question, we modeled changes in GPA using an latent difference score analysis (McArdle \& Hamagami, 2001) and then related the slope and intercept from this model to the self-esteem trajectory (Model 2). In LDS analysis, each observed score is decomposed into a latent variable and error. The change in this latent variable between two points of time is defined as a latent difference score. LDS analysis is optimal for a variable such as cumulative GPA because it includes an autoregressive component that explicitly models dependence of a score at one assessment with a score at a prior assessment. In the current 
study, each of the eight GPA assessments was indicated by a latent status variable. Latent difference scores were indicated by a variable with paths from previous status and to current status. To allow for estimation of the latent difference scores, the paths between all status variables and the paths between the latent difference score variable with current status were fixed at unity. Variances were estimated for each difference score. An intercept was specified by creating a path to the initial status variable, and a slope was specified by creating paths to all seven of the difference scores.

The GPA intercept and slope were then allowed to covary with the self-esteem variables. This conditional model yielded good fit, $\chi^{2}(81, N=295)=163.636, \mathrm{RMSEA}=.050,90 \%$ CI $[.046, .072], p_{\text {closefit }}=.128, \mathrm{CFI}=.986, \mathrm{TLI}=.984$. A significant association was found between the GPA slope and the 4-year self-esteem slope, indicating that increases in GPA were associated with increases in self-esteem (see Table 3 for estimates).

We next examined whether individuals who enter college expecting to receive high grades maintain their self-esteem, or experience a drop in self-esteem when they fail to meet their expectations. ${ }^{3}$ To address this question, we fit a conditional model (Model 3) in which a latent variable indicated by the three expected GPA items was entered as a predictor of the self-esteem variables. This conditional model yielded good fit, $\chi^{2}(32, N=295)=70.443$, RMSEA $=.064,90 \%$ CI $[.044, .084], p_{\text {closefit }}=.123, \mathrm{CFI}=.976, \mathrm{TLI}=.973$. Expected GPA had a significant effect on the self-esteem intercept, indicating that students who entered college with high expectations for academic achievement tended to have high levels of selfesteem. Expected GPA was also negatively associated with the 4-year slope, indicating that students who entered college with high expectations for academic achievement experienced a drop in self-esteem, or at least an attenuated increase, over the 4 years of college (see Table 4 for estimates).

To examine whether expected GPA predicts self-esteem independently of actual GPA, we next fit a conditional model (Model 4) in which both expected and actual GPA were entered as predictors of self-esteem. This conditional model yielded good fit, $\chi^{2}(118, N=295)=$ 224.123, RMSEA $=.055,90 \%$ CI $[.044, .066], p_{\text {closefit }}=.211, \mathrm{CFI}=.983, \mathrm{TLI}=.981$. All of the effects observed in Models 1 and 2 replicated in Model 3, and no new effects emerged (see Table 5 for estimates). Thus, expected GPA predicted the self-esteem trajectory independently of actual GPA. This suggests that individuals who entered college with unrealistically positive expectations about their grades—unrealistic relative to the grades they actually received - declined in self-esteem relative to those who entered college with more realistic appraisals of their academic future. Inclusion of the demographic covariates (Model 4a; see Figure 4) did not attenuate the significant effects of actual and expected GPA on the self-esteem intercept and self-esteem slope variables (see Table 5 for estimates).

${ }^{3}$ On average, the participants in our study "realistically" expected to attain a GPA of $3.43(S D=0.33$ ), yet the mean GPA at the end of the fourth year was $3.07(S D=0.47), .36$ grade points lower $(d=.90)$. Overall, $72 \%$ of participants expected to receive higher grades than they actually received. 


\section{Perceived Change in Self-Esteem}

In the previous section, we examined changes in scores on the Rosenberg Self-Esteem Scale over a 4-year period. In this section, we examine participants' subjective impressions of how they changed during college. $67 \%$ of our participants reported that their self-esteem had increased (score of 4 or 5), $21 \%$ reported that their self-esteem had stayed the same (score of 3 ), and only $12 \%$ reported that their self-esteem had declined (score of 1 or 2). Thus, the majority of participants believed their self-esteem improved during their 4 years in college, which is consistent with the observed increase in mean scores on the RSE. However, it is possible that these aggregate trends are consistent, yet at the individual level participants' perceptions of how they changed do not correspond with changes in the actual scores.

To examine the correspondence between perceived and actual change, we fit a conditional model (Model 5) where we entered perceived self-esteem change as a covariate of the selfesteem trajectory, regressing perceived self-esteem change onto the self-esteem intercept, first-semester slope, and 4-year slope (see Figure 5). The 4-year slope was positively associated with perceived changes in self-esteem (see Table 6), suggesting that individuals who thought they had increased (or decreased) in self-esteem did tend to actually increase (or decrease) in self-esteem, based on their RSE scale scores. Moreover, the self-esteem intercept was positively associated with perceived change, suggesting that individuals with higher initial levels of self-esteem tended to perceive themselves as gaining even more selfesteem as they progressed through college. The first-semester slope was not associated with perceived change, which is not surprising given that perceived change was assessed over the entire 4-year period, not just the first semester. The inclusion of demographic variables on perceived self-esteem change was not significant, indicating that the sex, race, and SES of the participant did not influence perceptions of self-esteem change (see Table 6 for coefficients). ${ }^{4}$

\section{Discussion}

The present research examined stability and change in self-esteem in a sample of young men and women followed longitudinally over 4 years of college. Given the centrality of academic achievement to the college experience, we also examined how specific aspects of academic achievement, such as grades earned throughout college and expectations for grades at the beginning of college, predicted individual differences in this self-esteem trajectory. In addition, one particularly unique feature of the present research is that we examined both actual and perceived changes in self-esteem, and how strongly individuals' perceptions of change correspond with actual changes in their self-esteem scores. Our findings contribute to a growing literature on how self-esteem changes throughout the life course by providing much needed data on the emerging adult period. Below we discuss the implications of the findings with regard to our central research questions.

\footnotetext{
${ }^{4}$ One interesting question is whether grades are associated with perceived change in self-esteem. We fit a model correlating GPA with perceived self-esteem change and found that GPA is not associated with perceived change in self-esteem. Thus, based on our data, changes in GPA are only associated with changes in "actual" self-esteem, but not with perceived self-esteem change.
} 


\section{Rank-Order Stability of Self-Esteem}

The current study sought to examine the stability of individual differences in self-esteem.

Our results show that stability was consistently high, indicating that people maintained their relative positions within the sample; those who entered college with high levels of selfesteem tended to leave college with high levels of self-esteem, and vice versa. The stability coefficients from the current study are comparable to or higher than what has been found in longitudinal studies of self-esteem and personality traits during young adulthood (Roberts \& DelVecchio, 2000; Robins, Fraley, et al., 2001; Trzesniewski et al., 2003; van der Velde et al., 1995). The high rank-order stability of self-esteem during this period suggests that, as individuals make the transition into adulthood, maturational changes are reduced, the sociocultural context is increasingly subject to individual control, and a more stable sense of self is formed. These processes would tend to promote continuity in self-concept over time and thus increase stability coefficients. These findings offer support for self-attitudes showing high levels of stability, which counters Conley's (1984) claim that personality traits and intelligence have higher levels of stability than self-attitudes. Our results also show that the variability of individual differences was significantly restricted during the time that average self-esteem levels were at their lowest. This finding suggests that the college transition affected students similarly and strongly during the first semester.

\section{Mean-Level Change in Self-Esteem}

The current study also sought to examine the trajectory of self-esteem throughout the entire college experience, an important issue that has received minimal attention in the research literature. Self-esteem was assessed three times during the first year of college, and then once a year for each subsequent year. Our results show that there is an average or typical trajectory and that it is nonlinear. On average, self-esteem is greatly impacted within the first year; it drops substantially during the first semester, suggesting that people are adversely affected by the initial transition into college. However, increases by the end of the first year suggest that people adapt somewhat quickly to the transition. Self-esteem continues to increase to above-initial levels by the end of college, suggesting that successfully navigating through the college years leads to an increased sense of self-worth. The current study supports previous longitudinal research showing that self-esteem declines during the first year of college (Pritchard et al., 2007; Shim et al., 2012) but is in contrast to previous research showing no change in self-esteem between the beginning and end of college (van der Velde et al., 1995). Additionally, the overall increase in self-esteem during college is consistent with recent studies showing that self-esteem increases during emerging adulthood (Erol \& Orth, 2011; Orth et al., 2010; Wagner et al., 2013), lending support for the "maturity principle," which states that as people age they increase on traits that reflect maturity and adaptability (Roberts \& Mroczek, 2008; Roberts, Wood, \& Caspi, 2008). Moreover, the increase in self-esteem is consistent with the patterns of personality change observed in the same sample. That is, the Big Five traits that tend to increase during college-extraversion, agreeableness, conscientiousness, and openness-are positively associated with self-esteem, whereas the Big Five trait that tends to decrease during college - neuroticism-is negatively associated with self-esteem (Robins et al., 2005; Robins, Tracy, et al., 2001). 


\section{Academic Achievement and Self-Esteem}

Although we were able to identify an average trajectory for self-esteem throughout college, our results show that there was significant individual variability around this trajectory.

Given the importance of academic achievement in college, we examined whether individual differences in academic achievement predicted individual differences in the self-esteem trajectory. Our results show that individuals who received better grades exhibited a greater increase in self-esteem over the 4 years of college. This finding extends previous research on the link between academic achievement and self-esteem by showing that changes in grades are associated with changes in self-esteem during the college years. Some previous studies have found that only academic self-esteem, not global self-esteem, is associated with academic achievement (e.g., Marsh \& Craven, 2006). However, the small but significant correlation we found between changes in global self-esteem and changes in grades is not surprising at a highly competitive university, where the stakes to perform well are high and where academic success is often central to the overall self-worth of academically talented students. If students are spending the majority of their waking hours engaged in academic activities, it makes sense that their self-esteem might be contingent on how well they perform academically, thus reflecting on their overall sense of self-worth, as well as their domain-specific evaluations of their academic competence.

Our results also show that the majority of our participants expected to earn better grades than they ended up receiving. Upon entering college, high expectations for grades appear to be beneficial for self-esteem, such that participants who have high expectations also have higher initial levels of self-esteem. However, these high expectations may make students more vulnerable to the inevitable failures that occur in a highly competitive academic context, negatively impacting self-esteem over time. Importantly, the adverse effect of high expectations on self-esteem change hold after controlling for the actual grades students received. This finding provides another illustration of how positive illusions (i.e., thinking one is going to get better grades than one actually does) might be associated with short-term benefits but long-term negative consequences (i.e., reduced growth in self-esteem throughout college) and supports previous research that characterizes such positive illusions as a "mixed blessing" (Paulhus, 1998; Robins \& Beer, 2001).

\section{Perceived Self-Esteem Change}

The present study also sought to examine people's perceptions of self-esteem change during the college years. Our results show that the majority of participants believed their selfesteem had changed. Although some reported that they thought their self-esteem had decreased, most reported that they thought their self-esteem had increased, similar to Robins, Fraley, et al.'s (2001) finding that the majority of participants believed they had changed on at least one of the Big Five. Why would this be the case? Systematic biases might prevent people from seeing their self-esteem in full light. For example, open-ended responses from participants in the present study suggest that people tend to view themselves as becoming more mature during college, consistent with Roberts' maturity principle. One student in our sample stated, 
I think I have changed tremendously since I entered college. I see myself as a stronger individual with distinct interests in a wider variety of things. I feel as if I have a lot more self-confidence and higher self-esteem. I am no longer as shy nor as naïve as I was. At the same time, I see myself as being more cynical and more defensive about romantic relationships. I enjoy my private time much more, and I feel much more mature and calmer than in my younger years.

Such perceptions may reflect stereotypes that some individuals have about how the college experience, or the transition to adulthood more generally, influences self-esteem development. To the extent that these stereotypes are differentially held, people will differ in the degree to which they overestimate how much they have changed, adding systematic error to the perception process. A related possibility is that changes in social roles and social context produce changes in behavioral patterns. For example, an individual who transitions from being a math major to a sociology major may experience a shift in the level of sociability among his or her peer group and show a corresponding belief that he or she has changed in extraversion. Such shift in the "ecology of the self" (Hormuth, 1990) may contribute to a shift in identity (and correspondingly a shift in perceived self-esteem).

The current study also sought to examine whether perceived changes in self-esteem correspond to actual changes in self-esteem scores. Our results show that people who actually did increase (or decrease) in self-esteem were more likely to perceive themselves as having increased (or decreased) in self-esteem, suggesting that people had some insight into how their self-esteem changed. This finding is consistent with the finding of Robins et al. (2005) that people's beliefs about change in the Big Five corresponded to actual change in scores on the NEO-FFI scales, and fails to support the claim that people have little insight into the way their personality changes (Costa \& McCrae, 1989; Herbst et al., 2000). Additionally, the frequent and often intense self-reflection that characterizes emerging adulthood might be one reason why we found such a large correspondence between perceived and actual change $(\beta=.56)$.

Of note, perceived changes in self-esteem showed a predicted pattern of associations with perceived changes in personality (assessed using the same 1-5 rating scale at Year 4). In the present sample, individuals who believed that their self-esteem had improved during college tended to perceive themselves as having become less neurotic $(r=-.38)$ and more extraverted ( $r=.41)$, agreeable $(r=.25)$, conscientious $(r=.18)$, and open to new experiences $(r=.30$; all $p \mathrm{~s}<.05)$. These correlations generally map onto the direction and magnitude of the relations found between measures of self-esteem and personality, except that the relation with neuroticism is somewhat weaker and the relation with openness somewhat stronger than is typically found (Robins, Tracy, et al., 2001).

\section{Limitations and Future Directions}

The present study has several limitations. First, our sample comes from a single, highly selective university, which may limit the generalizability of the results. That is, it may be something about the college experience at University of California, Berkeley in particular that leads to the self-esteem trajectory observed in the present study; it is possible that at less competitive universities, or at smaller universities that provide more academic and social 
support, students are less likely to experience a large drop in self-esteem during the first semester. Similarly, the time period during which data were collected (1992-1996) may have had a unique influence on the trajectory of self-esteem found in the current study. However, we found that this trajectory was robust across sex, socioeconomic status, and race, lending support for the turning point hypothesis, and suggesting that the effects of the transition into college on self-esteem are not specific to those at elite universities or to a specific time period. To further address this issue, we encourage researchers to examine a variety of present-day college student samples and other emerging adult samples.

Additionally, although we believe that the self-esteem drop occurs only during the initial transition to college, the design of the present study does not allow us to rule out the possibility that self-esteem also drops, and then rebounds, in subsequent years. Future studies can shed light on this issue by incorporating three waves of data collection in every year of college, not just Year 1 as in the present study.

Furthermore, the present study did not find links between academic achievement and the drop in self-esteem occurring during the first semester of college, suggesting that academic achievement and expectations for academic achievement did not influence self-esteem at this time. What else might predict this decrease? The fact that the first semester drop held for the vast majority of students (about six out of seven experienced a decline in self-esteem) suggests that normative factors might play a role. For example, it may be that self-esteem declines during the first semester because the major life transition of entering college entails a number of related experiences that adversely affect self-esteem including the feeling that one is no longer a big fish in a little pond, the difficulty of separating from one's parents, the need to establish a new peer group and initiate romantic relationships in a novel environment, and so on. Collectively these difficult life changes might damage, at least temporarily, most people's sense of self-worth. However, by the end of the first year, many of these issues have worked themselves out—students adapt to the idea that they are no longer the smartest kid in the class, they get used to and grow to appreciate the independence they now have from their parents, and eventually find a social niche that provides them with a sense of belonging.

The college experience inevitably involves a diverse range of experiences that extend beyond the academic domain-increased independence from one's family, romantic beginnings and endings, the establishment of life-long friendships, and shifting life goals. Amidst all these changing life circumstances, self-esteem exhibits impressive levels of continuity. Nonetheless, the degree of continuity is far from perfect, and people tend to have some insight into the way they change. Thus, further inquiry into the antecedents, concomitants, and consequences of different patterns of change is needed, both in terms of normative change and individual developmental trajectories.

Moreover, future studies may wish to examine similarities and differences in self-esteem trajectories and their correlates in high school graduates who attend college and those who do not. The present study confounds the normative maturational experience of transitioning from adolescence to emerging adulthood with the relatively common, but far from ubiquitous experience of going to college. Although we have interpreted the self-esteem 
trajectory identified in the present research as shaped by the college experience, it is possible that the changes we observed were due to maturational changes or broader social-contextual factors (e.g., changes in social roles) that are not unique to or dependent on the college experience. The long-term, 4-year increase in self-esteem seems more plausibly explained by such factors, whereas the precipitous, but highly normative drop in self-esteem that occurred during the first semester cannot be easily explained by more gradual maturational or social-contextual changes. A recent study provides some insight into this issue. Wagner et al. (2013) examined self-esteem change in a group of emerging adults who followed varying life paths, some went to college, whereas others obtained full-time employment, and some began long-term romantic relationships, whereas others remained single, and so on.

Consistent with the present findings, they found a gradual increase in self-esteem from age 19 to 25 . This trend held regardless of whether participants attended college. However, they did not assess self-esteem repeatedly during and immediately following each of these structural transitions. Research using a more intensive longitudinal design with frequent assessments of self-esteem in a sample of college students and an age-matched sample of non-college students would help disentangle these experiences and provide insights into the specific role that the college experience plays.

In addition, the current research could be extended to study generational changes. The present study consisted of participants who were college aged in 1996. The study could be repeated with contemporary college students. If claims of societal shifts are correct (e.g., Twenge, 2006), then we would expect that today's college students would (a) have higher mean-levels of self-esteem at all time points, (b) show a greater self-esteem decline and smaller rebound because they are unprepared for the harsher grading practices of college and separation from their overprotective, doting parents, and (c) be more likely to say they have changed for the better across the college years.

\section{Acknowledgments}

This research was supported by National Institute of Mental Health Predoctoral Fellowship T32-MH2006 to Joanne M. Chung and National Institute on Drug Abuse Grant R01-DA-017902 to Richard W. Robins.

\section{References}

Arnett, JJ. Emerging adulthood(s): The cultural psychology of a new life stage. In: Jensen, LA., editor. Bridging cultural and developmental psychology: New syntheses in theory, research and policy. Oxford University Press; New York, NY: 2011. p. 255-275.

Beyer S. Gender differences in the accuracy of grade expectancies and evaluations. Sex Roles. 1999; 41:279-296. doi:10.1023/A:1018810430105.

Blyth DA, Simmons RG, Bush D. The transition into early adolescence: A longitudinal comparison of youth in two educational contexts. Sociology of Education. 1978; 51:149-162. doi: $10.2307 / 2112661$.

Bollen, KA.; Curran, PJ. Wiley series on probability and mathematical statistics: Latent curve models: A structural equation approach. Wiley; Hoboken, NJ: 2006.

Caspi A, Roberts BW. Target article: Personality development across the life course: The argument for change and continuity. Psychological Inquiry. 2001; 12:49-66. doi:10.1207/ S15327965PLI1202_01. 
Conley JJ. The hierarchy of consistency: A review and model of longitudinal findings on adult individual differences in intelligence, personality and self-opinion. Personality and Individual Differences. 1984; 5:11-25. doi:10.1016/0191-8869(84)90133-8.

Costa, PT.; McCrae, RR. Personality continuity and the changes of adult life. American Psychological Association; Washington, DC: 1989. p. 41-77.doi:10.1037/10067-002

Crocker J, Luhtanen RK. Level of self-esteem and contin-gencies of self-worth: Unique effects on academic, social and financial problems in college students. Personality and Social Psychology Bulletin. 2003; 29:701-712. doi:10.1177/0146167203029006003. [PubMed: 15189626]

Donnellan MB, Kenny DA, Trzesniewski KH, Lucas RE, Conger RD. Using trait-state models to evaluate the longitudinal consistency of global self-esteem from adolescence to adulthood. Journal of Research in Personality. 2012; 46:634-645. doi:10.1016/j.jrp.2012.07.005. [PubMed: 23180899]

Donnellan MB, Trzesniewski KH, Robins RW, Moffitt TE, Caspi A. Low self-esteem is related to aggression, antisocial behavior, and delinquency. Psychological Science. 2005; 16:328-335. doi: 10.1111/j.0956-7976.2005.01535.x. [PubMed: 15828981]

Eccles JS, Wigfield A, Flanagan CA, Miller C. Self-concepts, domain values, and self-esteem: Relations and changes at early adolescence. Journal of Personality. 1989; 57:283-310. doi: 10.1111/j.1467-6494.1989.tb00484.x. [PubMed: 2769558]

Eccles JS, Wigfield A, Midgley C, Reuman D. Negative effects of traditional middle schools on students' motivation. The Elementary School Journal. 1993; 93:553-574. doi:10.1086/461740.

Erikson, EH. Childhood and society. Norton; New York, NY: 1964.

Erol RY, Orth U. Self-esteem development from age 14 to 30 years: A longitudinal study. Journal of Personality and Social Psychology. 2011; 101:607-619. doi:10.1037/a0024299. [PubMed: 21728448]

Farwell L, Wohlwend-Lloyd R. Narcissistic processes: Optimistic expectations, favorable selfevaluations, and self-enhancing attributions. Journal of Personality. 1998; 66:65-83. doi: 10.1111/1467-6494.00003. [PubMed: 9457770]

Fleeson W, Heckhausen J. More or less "me" in past, present, and future: Perceived lifetime personality during adulthood. Psychology and Aging. 1997; 12:125-136. doi: 10.1037/0882-7974.12.1.125. [PubMed: 9100273]

Garavalia LS, Gredler ME. An exploratory study of academic goal setting, achievement calibration and self-regulated learning. Journal of Instructional Psychology. 2002; 29:221-230.

Gosling SD, Rentfrow PJ, Swann WB. A very brief measure of the Big-Five personality domains. Journal of Research in Personality. 2003; 37:504-528. doi:10.1016/S0092-6566(03)00046-1.

Hansford BC, Hattie JA. The relationship between self and achievement/performance measures. Review of Educational Research. 1982; 52:123-142.

Harter, S. The construction of the self: A developmental perspective. Guilford Press; New York, NY: 1999.

Haslam N, Bastian B, Fox C, Whelan J. Beliefs about personality change and continuity. Personality and Individual Differences. 2007; 42:1621-1631. doi:10.1016/j.paid.2006.11.001.

Herbst JH, McCrae RR, Costa PT, Feaganes JR, Siegler IC. Self-perceptions of stability and change in personality at midlife: The UNC alumni heart study. Assessment. 2000; 7:379-388. doi: 10.1177/107319110000700406. [PubMed: 11151963]

Hirsch BJ, Rapkin BD. The transition to junior high school: A longitudinal study of self-esteem, psychological symptomatology, school life, and social support. Child Development. 1987; 58:1235-1243. doi:10.2307/1130617. [PubMed: 3665642]

Hormuth, SE. The ecology of the self: Relocation and self-concept change. Cambridge University Press; New York NY: 1990.

Kuster F, Orth U. The long-term stability of self-esteem: Its time-dependent decay and nonzero asymptote. Personality and Social Psychology Bulletin. 2013; 39:677-690. doi: 10.1177/0146167213480189. [PubMed: 23478674]

Kwan VSY, John OP, Kenny DA, Bond MH, Robins RW. Reconceptualizing individual differences in self-enhancement bias: An interpersonal approach. Psychological Review. 2004; 111:94-110. doi: 10.1037/0033-295X.111.1.94. [PubMed: 14756588] 
Marsh HW. Age and sex effects in multiple dimensions of self-concept: Preadolescence to early adulthood. Journal of Educational Psychology. 1989; 81:417-430. doi: 10.1037/0022-0663.81.3.417.

Marsh HW, Craven RG. Reciprocal effects of self-concept and performance from a multidimensional perspective: Beyond seductive pleasure and unidimensional perspectives. Perspectives on Psychological Science. 2006; 1:133-163.

Marsh HW, Hau K. Big-fish-little-pond effect on academic self-concept: A cross-cultural (26-country) test of the negative effects ofacademically selective schools. American Psychologist. 2003; 58:364-376. doi:10.1037/0003-066X.58.5.364. [PubMed: 12971085]

McArdle, JJ.; Hamagami, F. Latent difference score structural models for linear dynamic analyses with incomplete longitudinal data. American Psychological Association; Washington, DC: 2001. doi: 10.1037/10409-005

Noftle EE, Robins RW. Personality predictors of academic outcomes: Big Five correlates of GPA and SAT scores. Journal of Personality and Social Psychology. 2007; 93:116-130. doi: 10.1037/0022-3514.93.1.116. [PubMed: 17605593]

Nottleman, ED. Concurrent and predictive relations between hormone levels and socio-emotional functioning in early adolescence; Paper presented at the biennial meeting of the Society for Research in Child Development; Baltimore, MD. 1987;

Nowell C, Alston RM. I thought I got an A! Overconfidence across the economics curriculum. Journal of Economic Education. 2007; 38:131-142. doi:10.3200/JECE.38.2.131-142.

Orth U, Robins RW, Meier LL. Disentangling the effects of low self-esteem and stressful events on depression: Findings from three longitudinal studies. Journal of Personality and Social Psychology. 2009; 97:307-321. doi:10.1037/a0015645. [PubMed: 19634977]

Orth U, Robins RW, Roberts BW. Low self-esteem prospectively predicts depression in adolescence and young adulthood. Journal of Personality and Social Psychology. 2008; 95:695-708. doi: 10.1037/0022-3514.95.3.695. [PubMed: 18729703]

Orth U, Robins RW, Widaman KF. Life-span development of self-esteem and its effects on important life outcomes. Journal of Personality and Social Psychology. 2012; 102:1271-1288. doi:10.1037/ a0025558. [PubMed: 21942279]

Orth U, Trzesniewski KH, Robins RW. Self-esteem development from young adulthood to old age: A cohort-sequential longitudinal study. Journal of Personality and Social Psychology. 2010; 98:645658. doi:10.1037/a0018769. [PubMed: 20307135]

Pals JL. Identity consolidation in early adulthood: Relations with ego-resiliency, the context of marriage, and personality change. Journal of Personality. 1999; 67:295-329. doi: 10.1111/1467-6494.00057. [PubMed: 10202806]

Paulhus DL. Interpersonal and intrapsychic adaptiveness of trait self-enhancement: A mixed blessing? Journal of Personality and Social Psychology. 1998; 74:1197-1208. doi: 10.1037/0022-3514.74.5.1197. [PubMed: 9599439]

Postmes T, Haslam SA, Jans L. A single-item measure of social identification: Reliability, validity, and utility. British Journal of Social Psychology. 2012 Advance online publication. doi:10.1111/ bjso. 12006.

Pritchard ME, Wilson GS, Yamnitz B. What predicts adjustment among college students? A longitudinal panel study. Journal of American College Health. 2007; 56:15-22. doi:10.3200/ JACH.56.1.15-22. [PubMed: 17711821]

Roberts BW, DelVecchio WF. The rank-order consistency of personality traits from childhood to old age: A quantitative review of longitudinal studies. Psychological Bulletin. 2000; 126:3-25. doi: 10.1037/0033-2909.126.1.3. [PubMed: 10668348]

Roberts BW, Mroczek D. Personality trait change in adulthood. Current Directions in Psychological Science. 2008; 17:31-35. doi: 10.1111/j.1467-8721.2008.00543.x. [PubMed: 19756219]

Roberts, BW.; Wood, D.; Caspi, A. The development of personality traits in adulthood. In: John, OP.; Robins, RW.; Pervin, LA., editors. Handbook of personality: Theory and research. Guilford Press; New York, NY: 2008. p. 375-398. 
Robins RW, Beer JS. Positive illusions about the self: Short-term benefits and long-term costs. Journal of Personality and Social Psychology. 2001; 80:340-352. doi:10.1037/0022-3514.80.2.340. [PubMed: 11220450]

Robins RW, Fraley RC, Roberts BW, Trzesniewski KH. A longitudinal study of personality change in young adulthood. Journal of Personality. 2001; 69:617-640. doi:10.1111/1467-6494.694157. [PubMed: 11497032]

Robins RW, Hendin HM, Trzesniewski KH. Measuring global self-esteem: Construct validation of a single-item measure and the Rosenberg Self-Esteem Scale. Personality and Social Psychology Bulletin. 2001; 27:151-161. doi:10.1177/0146167201272002.

Robins RW, Noftle EE, Trzesniewski KH, Roberts BW. Do people know how their personality has changed? Correlates of perceived and actual personality change in young adulthood. Journal of Personality. 2005; 73:489-522. doi:10.1111/j.1467-6494.2005.00317.x. [PubMed: 15745439]

Robins RW, Pals JL. Implicit self-theories in the academic domain: Implications for goal orientation, attributions, affect, and self-esteem change. Self and Identity. 2002; 1:313-336. doi: $10.1080 / 15298860290106805$.

Robins RW, Tracy JL, Trzesniewski K, Potter J, Gosling SD. Personality correlates of self-esteem. Journal of Research in Personality. 2001; 35:463-482. doi:10.1006/jrpe.2001.2324.

Robins RW, Trzesniewski KH. Self-esteem development across the lifespan. Current Directions in Psychological Science. 2005; 14:158-162.

Rosenberg, M. Society and the adolescent self-image. Princeton University Press; Princeton, NJ: 1965.

Rutter M. Transitions and turning points in developmental psychopathology: As applied to the age span between childhood and mid-adulthood. International Journal of Behavioral Development. 1996; 19:603-626.

Schriber, RA.; Robins, RW. Self-knowledge: An individual-differences perspective. In: Vazire, S.; Wilson, TD., editors. Handbook of self-knowledge. Guilford Press; New York, NY: 2012. p. 105-127.

Shim SS, Ryan AM, Cassady J. Changes in self-esteem across the first year in college: The role of achievement goals. Educational Psychology. 2012; 32:149-167. doi: 10.1080/01443410.2011.627837.

Simmons RG, Blyth DA, Van Cleave EF, Bush D. Entry into adolescence: The impact of school structure, puberty, and early dating on self-esteem. American Sociological Review. 1979; 44:948967. doi:10.2307/2094719. [PubMed: 543570]

Staudinger UM, Bluck S, Herzberg PY. Looking back and looking ahead: Adult age differences in consistency of diachronous ratings of subjective well-being. Psychology and Aging. 2003; 18:1324. doi:10.1037/0882-7974.18.1.13. [PubMed: 12641309]

Svanum S, Aigner C. The influences of course effort, mastery and performance goals, grade expectancies, and earned course grades on student ratings of course satisfaction. British Journal of Educational Psychology. 2011; 81:667-679. doi:10.1111/j.2044-8279.2010.02011.x. [PubMed: 22050312]

Swann WB, Chang-Schneider C, Larsen McClarty K. Do people's self-views matter? Self-concept and self-esteem in everyday life. American Psychologist. 2007; 62:84-94. doi:10.1037/0003-066X. 62.2.84. [PubMed: 17324034]

Trzesniewski KH, Donnellan MB, Moffitt TE, Robins RW, Poulton R, Caspi A. Low self-esteem during adolescence predicts poor health, criminal behavior, and limited economic prospects during adulthood. Developmental Psychology. 2006; 42:381-390. doi: 10.1037/0012-1649.42.2.381. [PubMed: 16569175]

Trzesniewski KH, Donnellan MB, Robins RW. Stability of self-esteem across the life span. Journal of Personality and Social Psychology. 2003; 84:205-220. doi:10.1037/0022-3514.84.1.205. [PubMed: 12518980]

Twenge, JM. Generation me: Why today's young Americans are more confident, assertive, entitledand more miserable than ever before. Free Press; New York, NY: 2006.

Valentine JC, DuBois DL, Cooper H. The relation between self-beliefs and academic achievement: A meta-analytic review. Educational Psychologist. 2004; 39:111-133. 
van der Velde MEG, Feij JA, Taris TW. Stability and change of person characteristics among young adults: The effect of the transition from school to work. Personality and Individual Differences. 1995; 18:89-99.

Wagner J, Lüdtke O, Jonkmann K, Trautwein U. Cherish yourself: Longitudinal patterns and conditions of self-esteem change inthe transition to young adulthood. Journal of Personality and Social Psychology. 2013; 104:148-163. doi:10.1037/a0029680. [PubMed: 22889072]

Wendorf CA. Grade point average and changes in (great) grade expectations. Teaching of Psychology. 2002; 29:136-159. doi:10.1207/S15328023TOP2902_13.

White, RW. Lives in progress: A study of the natural growth of personality. 2nd ed.. Holt, Rinehart \& Winston; Oxford, England: 1966.

Wigfield A, Eccles JS. Children's competence beliefs, achievement values, and general self-esteem: Change across elementary and middle school. The Journal of Early Adolescence. 1994; 14:107138. doi:10.1177/027243169401400203.

Williams JM, Currie C. Self-esteem and physical development in early adolescence: Pubertal timing and body image. The Journal of Early Adolescence. 2000; 20:129-149. doi: $10.1177 / 0272431600020002002$.

Wilson AE, Ross M. From chump to champ: People's appraisals of their earlier and present selves. Journal of Personality and Social Psychology. 2001; 80:572-584. doi: 10.1037/0022-3514.80.4.572. [PubMed: 11316222]

Woodruff DS. The role of memory in personality continuity: A 25 year follow-up. Experimental Aging Research. 1983; 9:31-34. [PubMed: 6861838]

Woodruff DS, Birren JE. Age changes and cohort difference in personality. Developmental Psychology. 1972; 6:252-259. doi:10.1037/h0032086. 


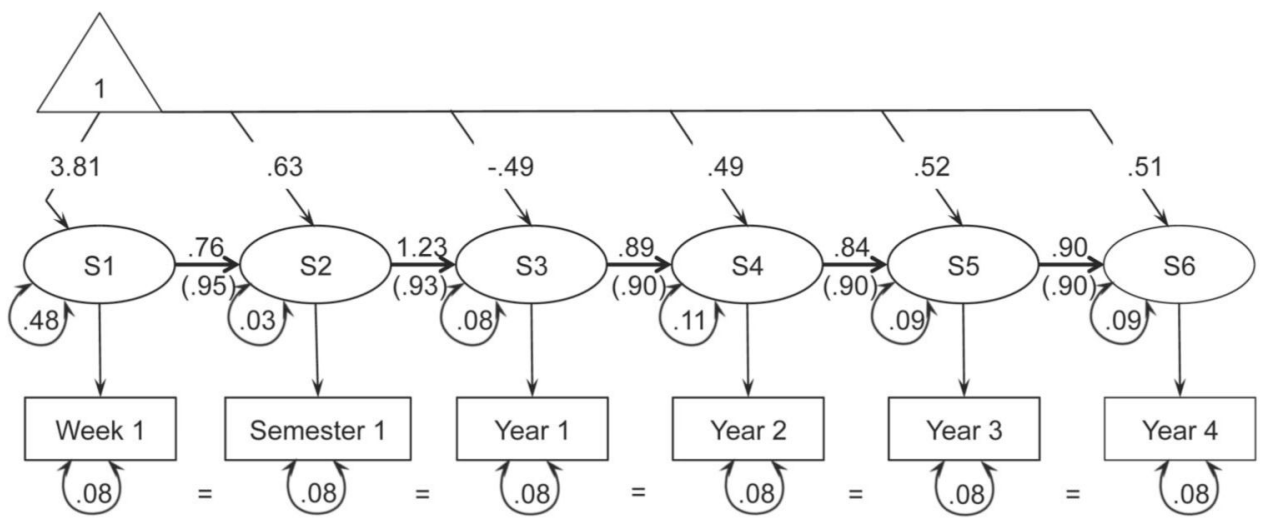

Figure 1.

First-order autoregressive model of self-esteem stability across 4 years of college.

Unstandardized estimates are presented in the figure. Standardized stability estimates are presented in parentheses. All estimates are significant at $p<.05$. The "S" denotes a latent status variable, which is indicated by the corresponding manifest variable (in rectangles). 


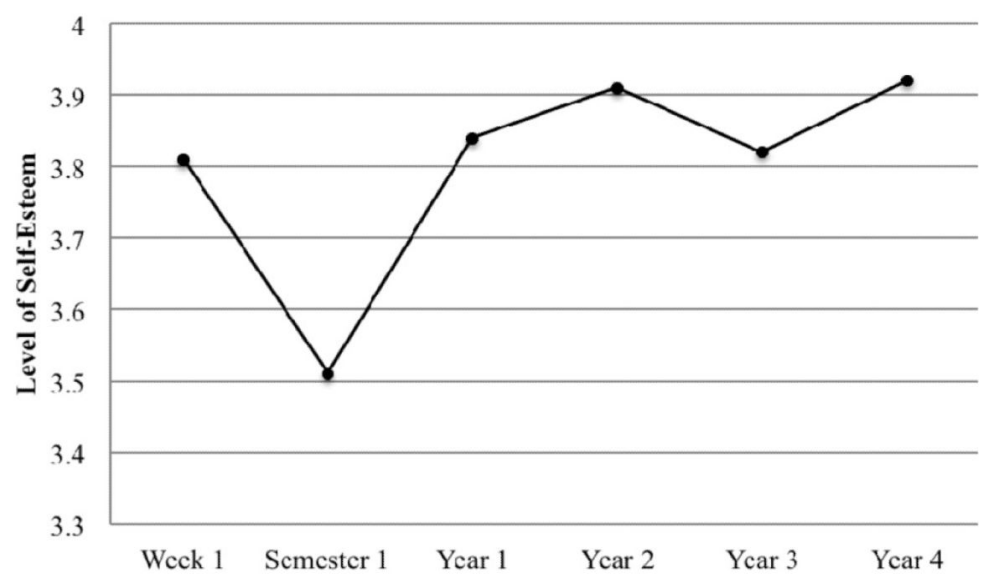

Figure 2.

Mean-level of self-esteem at each assessment. 


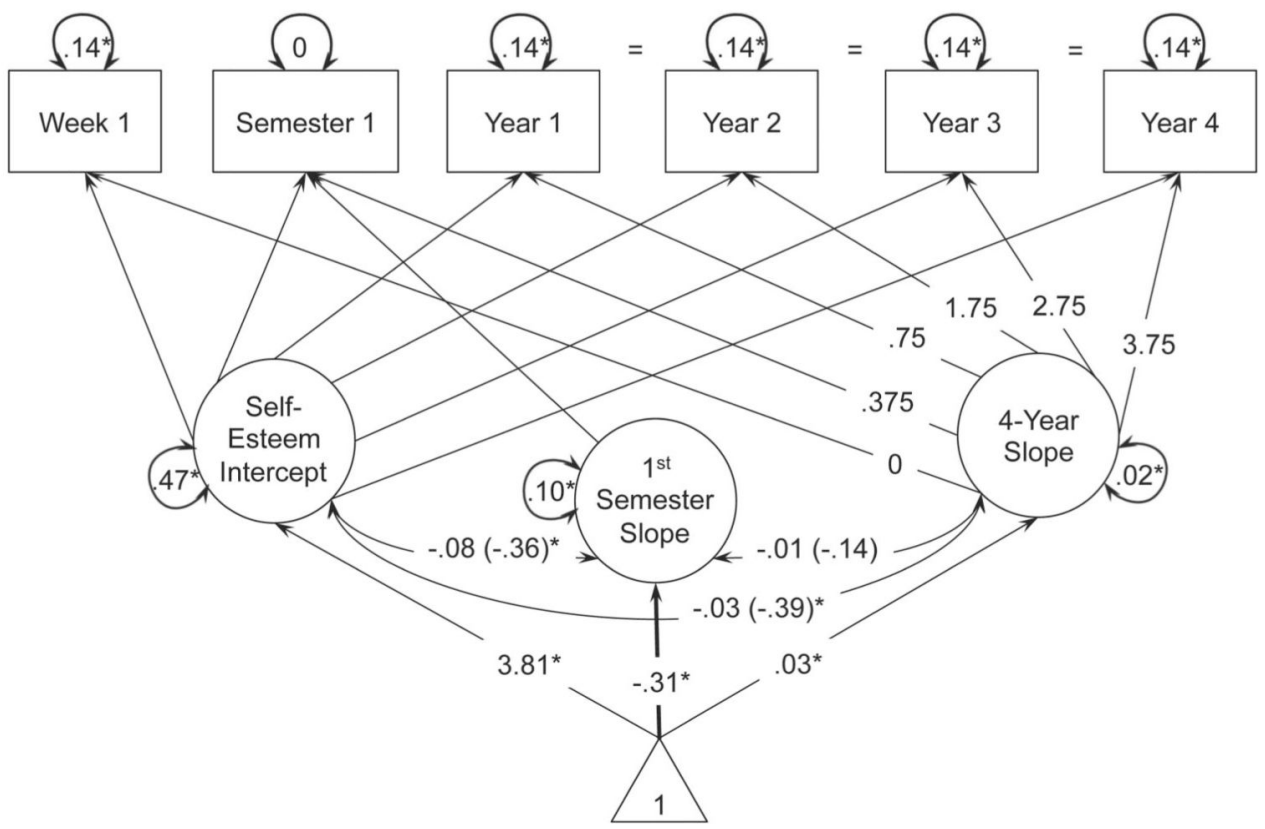

Figure 3.

Self-esteem trajectory (Model 0 -no covariates). Because the Semester 1 assessment occurred about three and a half months after Week 1, the path from latent slope to Semester 1 was fixed at .375 . The path from latent slope to the Year 1 assessment was fixed at .75 to represent another difference of three and a half months. Each subsequent assessment was collected yearly, and thus the path from latent slope to Year 2 assessment was fixed at 1.75; for the Year 3 assessment, fixed at 2.75; and for the Year 4 assessment, fixed at 3.75. Unstandardized estimates are presented in the figure. Standardized estimates are in parentheses. In a previous iteration of this model, the residual variance estimate of the Semester 1 assessment was negative, representing a Heywood case. However, the residual variance of the Semester 1 assessment was not significantly different from 0 , and, consequently, the Semester 1 assessment was fixed at 0 to allow for more appropriate estimates. $* p<.05$. 


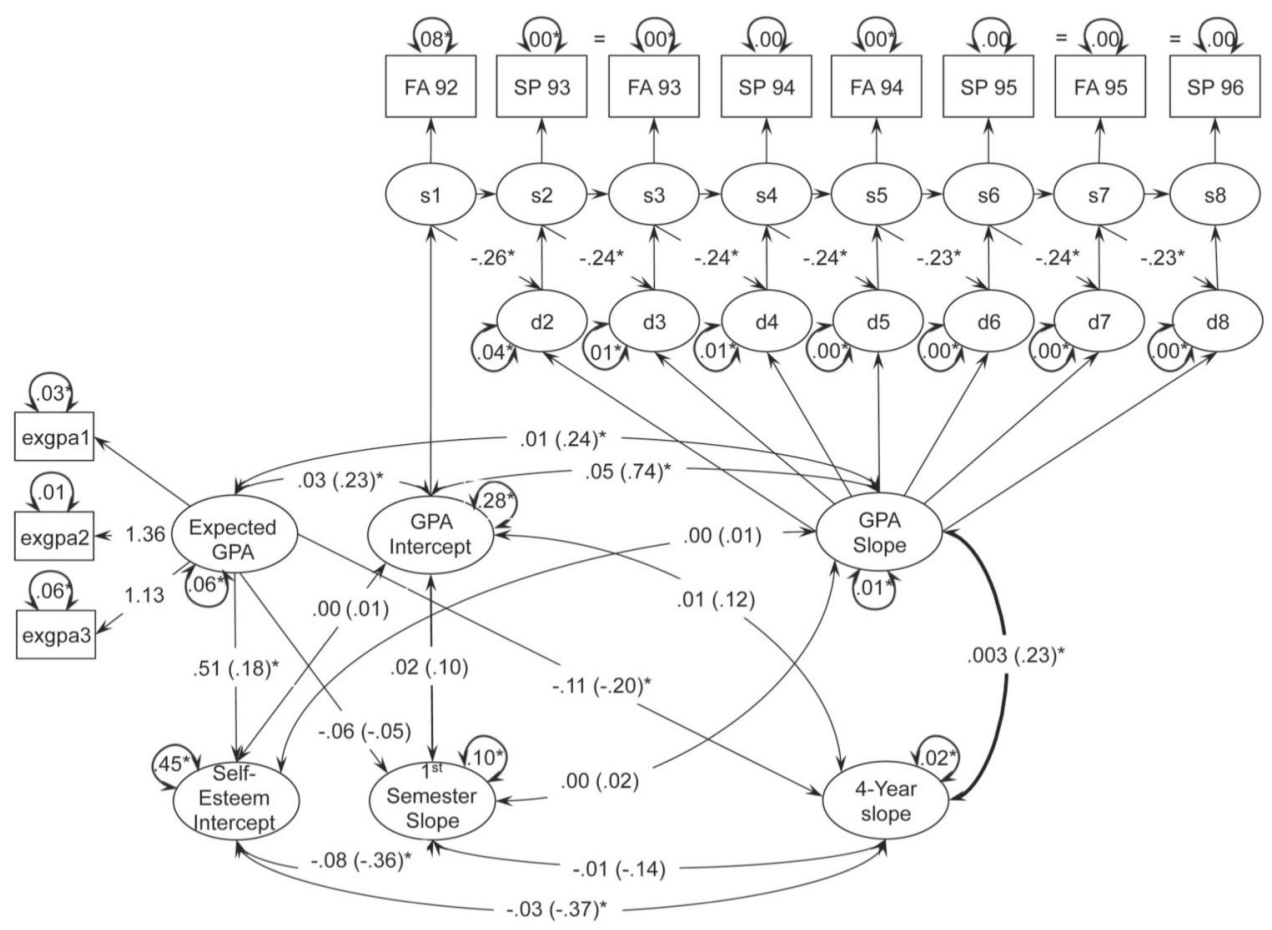

Figure 4.

Effects of actual and expected grade-point average (GPA) on self-esteem-trajectory (Model 4a). The unit constant and associated means are omitted from the figure for simplicity. Manifest variables for self-esteem trajectory are omitted from the figure. Coefficients for demographic variables are presented in Table 5. Unstandardized estimates are presented in the figure. Standardized estimates are in parentheses. "FA92" refers to the manifest variables for GPA at the end of fall semester in 1992, and "SP93" refers to the manifest variable for GPA at the end of spring semester in 1993, and so on. The "s" projecting on to these variables refers to the latent status variables for GPA, and the "d" refers to the latent difference scores for GPA. "exgpa1" refers to the manifest variable, "What overall GPA do you think you are capable of attaining at UC Berkeley?" "exgpa2" refers to the manifest variable, "Realistically, what overall GPA do you think you will attain at UC Berkeley?" "exgpa3" refers to the manifest variable, "What is the lowest overall GPA you would be satisfied attaining at UC Berkeley?" * $p<.05$. 


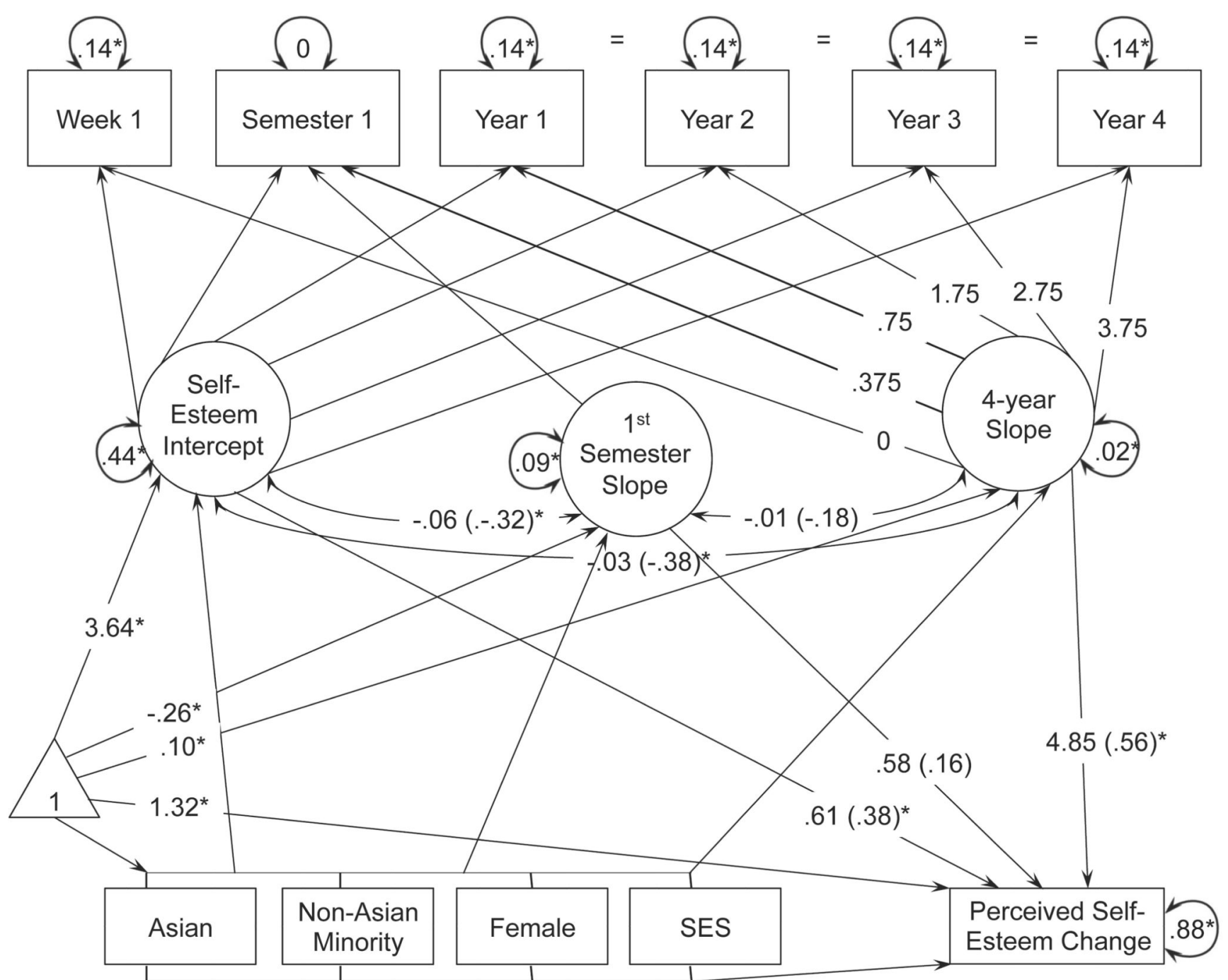

Figure 5.

Correspondence between self-esteem trajectory and perceived self-esteem change (Model 5). Coefficients for demographic variables are presented in Table 6. Unstandardized estimates are presented in the figure. Standardized estimates are in parentheses. SES = socioeconomic status. ${ }^{*} p<.05$. 


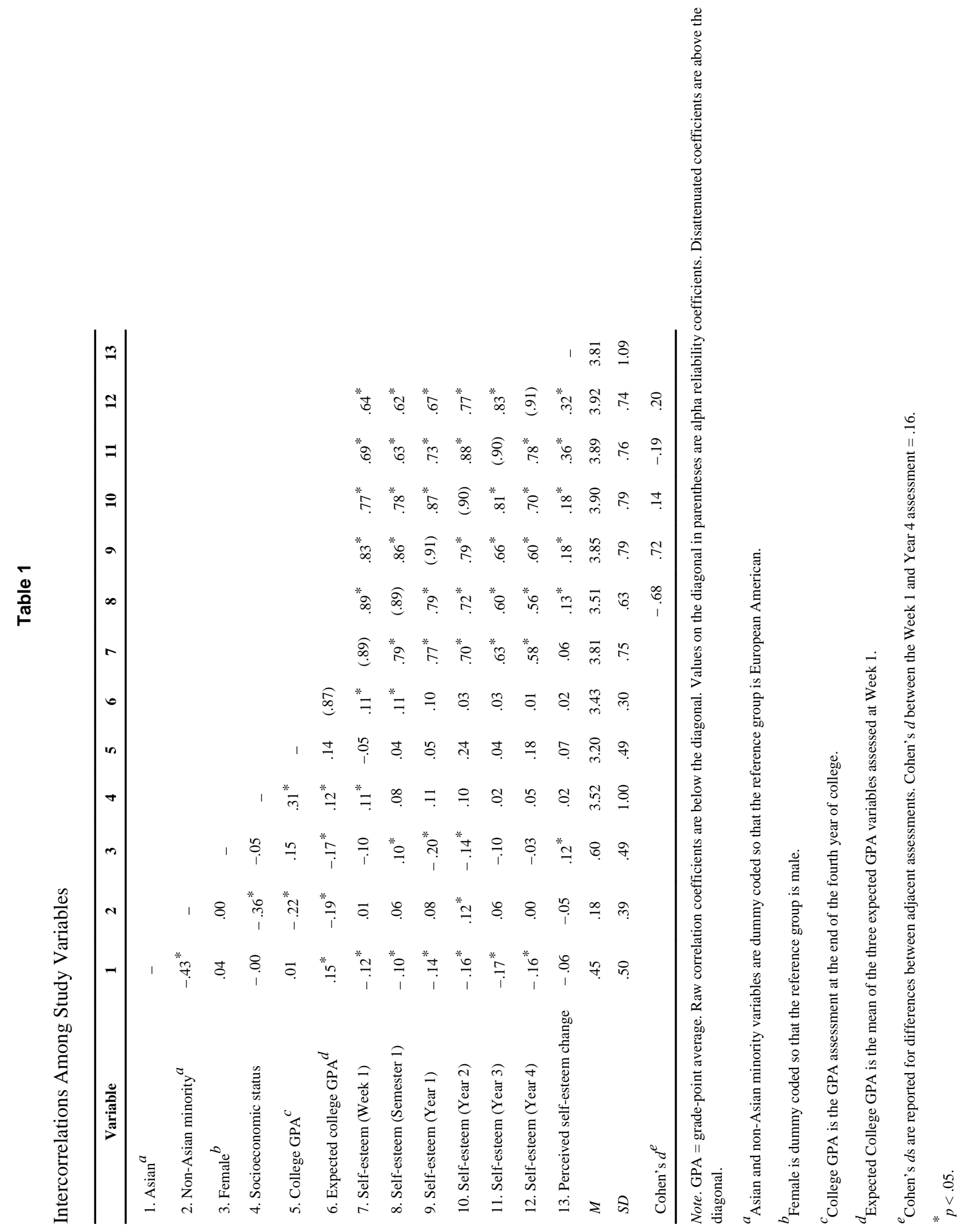


Table 3

Model 2: Effects of College GPA on Self-Esteem-Trajectory

\begin{tabular}{|c|c|c|c|c|c|c|}
\hline \multirow[b]{2}{*}{ Variable } & \multicolumn{3}{|c|}{ GPA intercept } & \multicolumn{3}{|c|}{ GPA slope } \\
\hline & $B$ & $S E B$ & $\beta$ & $B$ & $S E B$ & $\beta$ \\
\hline Self-esteem intercept & .02 & .03 & .05 & .00 & .01 & .05 \\
\hline Self-esteem slope: First semester & .02 & .02 & .09 & .00 & .00 & .01 \\
\hline Self-esteem slope: 4 years & .00 & .01 & .06 & .00 & .00 & $.17^{*}$ \\
\hline
\end{tabular}

Note. GPA = grade-point average.

* $p<.05$. 
Table 4

Model 3: Effects of Expected GPA on Self-Esteem-Trajectory

\begin{tabular}{lccc}
\hline & \multicolumn{3}{c}{ Expected GPA } \\
\cline { 2 - 4 } \multicolumn{1}{c}{ Variable } & $\boldsymbol{B}$ & $\boldsymbol{S} \boldsymbol{E} \boldsymbol{B}$ & $\boldsymbol{\beta}$ \\
\hline Self-esteem intercept & .52 & .19 & $.18^{*}$ \\
Self-esteem slope: First semester & -.06 & .11 & -.05 \\
Self-esteem slope: Four years & -.11 & .05 & $-.20^{*}$ \\
\hline
\end{tabular}

Note. GPA = grade-point average.

* $p<.05$. 
Table 5

Models 4 and 4a: Effects of Actual and Expected GPA on Self-Esteem-Trajectory (With and Without Demographic Covariates)

\begin{tabular}{|c|c|c|c|c|c|c|c|c|c|}
\hline \multirow[b]{2}{*}{ Predictor } & \multicolumn{3}{|c|}{ Self-esteem intercept } & \multicolumn{3}{|c|}{$\underline{\text { Self-esteem slope: First semester }}$} & \multicolumn{3}{|c|}{ Self-esteem slope: 4 years } \\
\hline & $\boldsymbol{B}$ & $S E B$ & $\beta$ & $\boldsymbol{B}$ & $S E B$ & $\boldsymbol{B}$ & $\boldsymbol{B}$ & $S E B$ & $\beta$ \\
\hline GPA intercept & $.00 / .01$ & $.02 / .02$ & $.01 / .08$ & $.02 / .01$ & $.01 / .01$ & $.10 / .09$ & $.01 / .01$ & $.01 / .01$ & $.12 / .08$ \\
\hline GPA slope & $.00 / .00$ & $.01 / .01$ & $.01 / .02$ & $.00 / .00$ & $.00 / .00$ & $.02 / .00$ & $.00 / .00$ & $.00 / .00$ & $.23 \% .18 *$ \\
\hline Expected GPA & $.51 / .50$ & $.19 / .19$ & $.18 \% 1.18 *$ & $-.06 /-.05$ & $.11 / .11$ & $-.05 /-.04$ & $-.11 /-.09$ & $.05 / .05$ & $-.20 *-.17 *$ \\
\hline Female & $-/-.16$ & -1.09 & $-/-.12$ & $-/ .09$ & $-/ .05$ & $-/ .15$ & $-/ .03$ & $-/ .02$ & $-/ .11$ \\
\hline Asian & $-/-.15$ & $-/ .10$ & $-/-.11$ & $-/ .07$ & -1.06 & $-/ .11$ & $-/-.04$ & $-/ .02$ & $-/-.15$ \\
\hline Non-Asian minority & -1.18 & $-/ .13$ & $-/ .10$ & $-/-.08$ & -1.08 & $-/-.10$ & $-/-.07$ & $-/ .03$ & $-/-.20^{*}$ \\
\hline SES & $-/ .09$ & $-/ .05$ & $-/ .13$ & $-1-.03$ & $-/ .03$ & $-/-.11$ & $-1-.02$ & $-/ .01$ & $-/-.14$ \\
\hline
\end{tabular}

Notes. GPA = grade-point average. Model 4 estimates (without demographic covariates) are on the left of the backslash, and Model 4a estimates (with demographic covariates) are on the right. Dashes denote that the variable was not entered into the model.

* $p<.05$. 
Table 6

Association Between Actual and Perceived Change in Self-Esteem, With and Without Demographic Covariates

\begin{tabular}{|c|c|c|c|c|c|c|}
\hline \multirow[b]{3}{*}{ Predictor } & \multicolumn{6}{|c|}{ Perceived change in self-esteem } \\
\hline & \multicolumn{3}{|c|}{$\begin{array}{c}\text { No demographic } \\
\text { covariates }\end{array}$} & \multicolumn{3}{|c|}{$\begin{array}{c}\text { Demographic } \\
\text { covariates included } \\
\end{array}$} \\
\hline & $\boldsymbol{B}$ & $S E B$ & $\beta$ & $\boldsymbol{B}$ & $S E B$ & $\boldsymbol{B}$ \\
\hline Self-esteem intercept & .61 & .14 & $.38^{*}$ & .61 & .14 & $.38^{*}$ \\
\hline $\begin{array}{l}\text { Self-esteem slope: } \\
\text { First semester }\end{array}$ & .62 & .39 & .18 & .58 & .42 & .16 \\
\hline Self-esteem slope: 4 years & 4.93 & 1.10 & $.57^{*}$ & 4.85 & 1.16 & $.56^{*}$ \\
\hline Female & - & - & - & .17 & .15 & .08 \\
\hline Asian & - & - & - & -.00 & .15 & .00 \\
\hline Non-Asian minority & - & - & - & -.05 & .22 & -.01 \\
\hline Socioeconomic status & - & - & - & .05 & .08 & .04 \\
\hline
\end{tabular}

Note. $R^{2}=.26$ in both models. Dashes denote that the variable was not entered into the model. * $p<.01$. 